\title{
Physiotherapeutic management strategies for the treatment of cystic fibrosis in adults
}

\author{
This article was published in the following Dove Press journal: \\ Journal of Multidisciplinary Healthcare \\ 18 November 2010 \\ Number of times this article has been viewed
}

\section{Tracey Daniels}

York Hospitals NHS Trust Cystic Fibrosis Unit, York Teaching Hospitals Foundation NHS Trust, York, UK

Correspondence:Tracey Daniels Physiotherapy Department, York Hospital, York, Y03।8HE, UK

Tel +44 I904725389

Email traceydaniels I@nhs.net
Abstract: Physiotherapy has long been considered a cornerstone of condition management for people with cystic fibrosis (CF). The presentation of CF has changed over time with an increased life expectancy and increased expectations of people with $\mathrm{CF}$ to have a complete lifestyle. In turn, the scope of strategies used in physiotherapy for CF have also changed dramatically over the years, moving away from routine postural drainage and manual techniques toward an individualized regimen including the choice of many different forms of airway clearance, such as both independent and assisted, exercise, treatments to promote continence and good posture, inhalation therapy, oxygen, and noninvasive ventilation. This article describes the techniques and overall strategies used by physiotherapists in helping people with CF to manage the symptoms and progression of their condition.

Keywords: airway clearance, exercise, inhalers, nebulizers, oxygen, noninvasive ventilation

\section{Introduction}

Cystic fibrosis (CF) is the most common life-limiting genetic disease in the Caucasian population and is also found in other ethnic groups. It is a multisystem disorder, although the main cause of morbidity and mortality is respiratory failure. The median life expectancy has increased significantly over the last two decades and is currently in the mid-thirties. ${ }^{1}$ A factor in the improvement of life expectancy is an increase in the range and intensity of treatments including nutritional support, physiotherapy, antibiotics, and other medications.

Physiotherapy has a long-standing role in the management of CF; conventional physiotherapy consisting of postural drainage and manual techniques is described in papers from 1970s, but this aspect of management has changed dramatically over time alongside the presentation of people with CF. Life expectancy has improved as have the expectations of people with $\mathrm{CF}$ who generally wish to achieve the normal milestones, such as attending school, university and work, getting married, and having their own family. This provides challenges in balancing the optimal treatment needed to maintain the health status required to achieve these milestones with the burden of treatment that may also affect lifestyle.

In order to balance treatment demands and lifestyle, methods of management have been developed to allow patients who wish to complete treatments at home and/or independently to do so where clinically possible thus avoiding extended periods of time in the hospital environment and dependence on others that affect the personal life of people with CF and may have financial implications for the health care provider. 
Therefore, contemporary management strategies utilized by physiotherapists focus on independence and maintaining a normal lifestyle, which is reflected in the use of the techniques described.

There are challenges in conducting high-quality research assessing physiotherapeutic techniques in people with CF. CF itself has a variable disease process with periods of stability, periods of exacerbation, and a varying rate of decline. Those with CF are a highly studied population and so it can be difficult to recruit them to physiotherapy studies. There are also methodological issues with assessing physiotherapy interventions; blinding is generally very difficult. The aim of this review is to present the range of physiotherapeutic interventions, to summarize the evidence that exists, and to highlight gaps in the knowledge base.

\section{Airway clearance}

Good airway clearance remains a key aim of physiotherapy for people with $\mathrm{CF}$ and is considered to be integral to their overall management. ${ }^{2}$ There are many techniques available that require different patient ability and different types of equipment with varying space, portability, noise, appearance and cost characteristics. In the United Kingdom (UK), the most common forms of airway clearance used are conventional physiotherapy, active cycle of breathing techniques (ACBT), autogenic drainage (AD), positive expiratory pressure (PEP) devices, oscillating PEP devices, noninvasive ventilation (NIV), and exercise. However physiotherapists and people with CF will often choose to try new forms of airway clearance that become available. Recently, this has led to some use of high-frequency chest wall oscillation (HFCWO), intrapulmonary percussive ventilation (IPV), cough assist, respiratory muscle training, and other techniques.

The question of whether there is evidence that airway clearance should be offered has often been raised. There are no long-term trials of physiotherapy for airway clearance versus no physiotherapy for airway clearance. This is not surprising as physiotherapy is regarded as such an integral aspect of CF care that there are questions around the ethics of carrying out such a trial and whether those involved, people with CF, clinicians, and families, would feel comfortable in taking part in such a trial. However, there is evidence from two reviews of short-term trials of physiotherapy versus no physiotherapy. ${ }^{3,4}$ These reviews suggest that physiotherapy does increase sputum transport as compared with no physiotherapy.

Recent UK guidance has suggested that an airway clearance technique be taught to improve sputum transport, ${ }^{5}$ whereas a second set of recommendations from the United States stated that airway clearance should be offered to all patients with CF as there is high certainty that the net benefit is moderate and at least moderate certainty that the net benefit is moderate to substantial. ${ }^{6}$ So the question is not whether we should be offering airway clearance to people with CF but rather what type of airway clearance we should offer to people with $\mathrm{CF}$.

\section{Conventional physiotherapy}

Conventional physiotherapy is a combination of postural drainage, components of the ACBT, huffing, directed coughing, and manual techniques ${ }^{7}$ that can include percussion, which is the rhythmical clapping of the chest wall, chest shaking, and vibrations, which are vibratory movements applied to the chest wall during expiration. ${ }^{8}$

Conventional chest physiotherapy (CCPT) is comparable in terms of effectiveness with other airway clearance techniques $^{7}$ and it remains a combination of techniques that some people find useful and have a preference for. However, it does have drawbacks that have become more evident as people have moved toward independent lifestyles, which are not always based around the home. Space and/or equipment are required to facilitate postural drainage and it may be difficult to perform manual techniques independently.

\section{Active cycle of breathing techniques}

The ACBT is a cycle of techniques consisting of the following three components: (1) breathing control that is tidal volume breathing encouraging use of the lower chest with relaxation of the upper chest and shoulders, (2) thoracic expansion involving deep breathing with an emphasis on inspiration with or without breath hold then quiet, relaxed expiration, and (3) forced expiration technique consisting of one or two huffs; a forced breath out through an open mouth.

ACBT increases the rate of expectoration, so reducing time required for physiotherapy, ${ }^{9}$ and is as effective when done independently as with assistance both in terms of energy expenditure $^{10}$ and on the amount of sputum cleared. ${ }^{9}$ It is as effective as AD, ${ }^{11}$ PEP, cornet or flutter. ${ }^{12}$ ACBT has the advantage of being a relatively simple technique requiring no equipment or assistance if used in isolation. It may also be combined with other physiotherapy techniques, such as postural drainage and percussion. ${ }^{7}$

\section{Autogenic drainage}

$\mathrm{AD}$ is a breathing technique that aims to maximize airflow within the airways using controlled breathing at differing 
lung volumes to reach the highest possible airflow in the different generations of bronchi. ${ }^{13}$ The technique involves (1) slow inspiration encouraging use of the diaphragm and maintaining an open upper airway, (2) an inspiratory pause maintaining an open glottis, and (3) an expiratory breath that should be at the highest velocity possible without causing airway narrowing. This breathing technique is carried out at tidal volume within differing lung volumes, so maximizing expiratory flow. This is often described as a three-phase technique as follows: (1) unstick - this phase is carried out at low lung volume to help to loosen the peripherally situated secretions, (2) collect - breathing around mid-lung volume facilitates collection of secretions in the upper airways, and (3) evacuate - breathing at high lung volume facilitates clearance of secretions from the upper airways. ${ }^{13}$

$\mathrm{AD}$ is equivalent in effectiveness to conventional physiotherapy in terms of sputum clearance and respiratory function. ${ }^{7,14,15}$ Compared with ACBT, it has been found to be a faster method of clearing sputum; however no differences in sputum weight cleared or in lung function have been identified. ${ }^{11}$ In a comparison with high pressure PEP (Hi-PEP), described later, AD gives an improved lung function, but sputum clearance is increased with Hi-PEP. ${ }^{16}$

$\mathrm{AD}$ uses no equipment and requires little space as it can be performed in sitting and it may also be combined with other physiotherapy techniques. However it may be a difficult technique for the person with $\mathrm{CF}$ to understand and to learn particularly if they are not big producers of sputum and so do not get audio feedback of the movement of sputum. However some physiotherapists do use this technique in very young children and, with careful education, most people with $\mathrm{CF}$ should become competent at using it. A patient preference for $\mathrm{AD}$ has been shown elsewhere; ${ }^{14,15}$ in a past study of eighteen patients, eight refused to revert back to CCPT from AD to complete the trial and another five continued with $\mathrm{AD}$ while supposedly doing CCPT. ${ }^{14}$

\section{PEP devices}

PEP devices provide a resistance on expiration so theoretically improving sputum clearance by increasing gas pressure behind sputum via collateral ventilation. ${ }^{17,18}$ PEP may also stabilize airways by splinting them open during expiration so facilitating sputum clearance. ${ }^{19} \mathrm{PEP}$ was originally defined as breathing with a PEP of $10-25 \mathrm{~cm} \mathrm{H}_{2} \mathrm{O},{ }^{20}$ but this definition was expanded for a Cochrane Review in 2006 to include pressures from 5-25 cm $\mathrm{H}_{2} \mathrm{O} .{ }^{16}$ PEP devices are commonly used in the form of a sealed mask held against the face or a mouthpiece sealed between the lips. Both types of device incorporate a one-way inspiratory valve and an expiratory resistance is provided by a resistor or hole of varying diameter that can be altered to tailor the resistance to the patient. A manometer can be added to the PEP device to measure the expiratory pressure with a given resistor until the appropriate pressure is achieved at mid-expiration. During use, the person with CF inhales to a mid-lung volume and actively exhales; a number of breaths will be completed followed by relaxed breathing and forced expiratory technique as required. This cycle is repeated and the number of cycles and exact routine of breaths with PEP, relaxed breathing, and forced expiratory technique is individualized to person using it. Mouthpiece PEP devices may also be used as an attachment to some nebulizers, so providing PEP during nebulization.

Hi-PEP is a modification of a PEP device that includes a complete forced expiration against a fixed mechanical resistance, which usually generates pressures ranging from 40-100 $\mathrm{cm} \mathrm{H}_{2} \mathrm{O}$, and may stimulate coughing. ${ }^{19}$ The size of the resistor is assessed when the patient is performing forced volume vital capacity (FVC) maneuvers through each level of resistance while the mask is connected to a spirometer or pneumatograph. The correct resistor will give a flow volume curve with a maximal FVC demonstrating a long spell of constant expiratory flow. ${ }^{5}$

PEP has been demonstrated to be equivalent in effectiveness to other commonly used techniques such as ACBT, $\mathrm{AD}$, cornet, and flutter when used over 1 year. ${ }^{21}$ There have been suggestions in papers prior to this study that PEP may be superior to oscillating PEP for reducing hospital admissions ${ }^{22,23}$ and superior to other forms of airway clearance for sputum clearance. ${ }^{20,24,25}$ However, the decision to use PEP over another technique needs to be individually assessed as the evidence is not robust enough to apply this to all patients. There are some concerns that Hi-PEP may be of higher risk to the person using it because of the pressures involved, but this has not been proven.

$\mathrm{PEP}$ is a relatively simple technique using equipment that is small enough to be portable. It may be combined with other airway clearance techniques and may be used independently. PEP has been found to be more acceptable to patients than other airway clearance techniques when used in studies of over one month in duration.

\section{Oscillating PEP devices}

Oral oscillatory PEP devices include flutter, cornet, and acapella. ${ }^{16}$ Theoretically, they work in the same way as PEP devices but also shear sputum from the airways by vibration and alter the sputum structure by potentially thinning it. 
The flutter is a pipe-type device made from hard plastic with a perforated cover encasing a stainless steel ball within a plastic cone. As the person exhales through the flutter, the ball bounces and rolls within the cone creating interruptions in expiratory flow and producing a PEP of $10-25 \mathrm{~cm} \mathrm{H}_{2} \mathrm{O}$ and a vibratory frequency of about $15 \mathrm{~Hz}$. The technique used is similar to that of PEP with an inspiration to midvolume, but this cannot be made through the PEP as there is no inspiratory/expiratory valve. Therefore, the person breathes in either through their nose or with an open mouth around the mouthpiece. The mouth is then sealed around the mouthpiece and an active expiration is made while the person tries to keep the cheeks stiff, losing as little vibration through the cheeks as possible. A cycle of breaths through the flutter is interspersed with relaxed breathing and forced expiratory technique; the exact cycle used is individualized. ${ }^{5}$

The acapella is a plastic device that utilizes a counterweighted plate and magnet to create PEP and oscillation with interruptions to expiratory flow similar to that seen with flutter. The acapella choice has a dial to set expiratory resistance, can be used via mouthpiece or mask and may be used with a nebulizer in-line. The technique for use is similar to flutter, but unlike the flutter, inspiration may be through the device. It also has the advantage that it is nonpositional, ie, can be used at any angle. ${ }^{5}$

The RC-cornet ${ }^{\circledR}$ (Bonicur Ltd, Middlesex, United Kingdom) is a flat rubber hose within a plastic arched tube. The hose lies flat against the tube until it reaches the curve where it kinks. During expiration through the tube, the hose fills with air until the kink causes an interruption to the expiratory flow until the kink moves along the tube and a new kink is formed closer to the mouthpiece. These interruptions cause an oscillation in the same way as flutter and acapella. The use of the RC-cornet is similar to flutter and acapella, and like the acapella, it is nonpositional and can be used with a nebulizer in-line. ${ }^{5}$

One study made a long-term (one year) comparison of $\mathrm{ACBT}, \mathrm{AD}, \mathrm{RC}$-cornet, flutter, and PEP and found no significant differences in the effectiveness of these techniques for airway clearance in adults with $\mathrm{CF}^{21}$ Other studies have demonstrated conflicting results with an increase in sputum expectoration shown as compared with other techniques ${ }^{26}$ and evidence that oscillating PEP is less effective than PEP in terms of hospital admissions and respiratory function..$^{22,23}$ These studies assessed flutter although acapella has been shown to have similar characteristics and may even have slightly better performance characteristics than the flutter in terms of the stability of the oscillation wave form. ${ }^{27}$

All of the identified oscillatory PEP devices are small and therefore portable. They are relatively inexpensive and adaptable as they can all be used alongside other airway clearance techniques. Some people with CF, particularly those who have previously used manual techniques, find that the sensation of vibration with oscillating PEP as opposed to PEP makes them feel that the technique is working. There are suggestions of patient preference for oscillating PEP over other techniques. However there is noise created by oscillating PEP devices, particularly RC-cornet, and some patients do find this to be unacceptable.

\section{Noninvasive ventilation}

NIV refers to ventilatory support given through the upper airway provided via a mask, mouthpiece, or similar. ${ }^{28}$ There are many types of ventilator available that provide single level, bi-level, or volume support. There is also a wide range of interfaces available including types of mouthpiece, nasal pillows, oral, nasal, complete, or total facemasks.

Depending on the situation, the physiotherapist will use either a mask or more commonly a mouthpiece when using NIV for airway clearance. This makes removal of the NIV quicker and easier when coughing and clearing sputum. The pressures used for airway clearance may be different to the pressures used for overnight or similar use and the physiotherapist ensures that these pressures are sufficient to gain optimal chest expansion during inspiration for the person using it. A version of ACBT is generally used with NIV facilitating thoracic expansion and decreasing the work of breathing during relaxed breathing. Some people may also use NIV to achieve a deep inspiration before the forced expiratory technique and to recover after cough.

During airway clearance with NIV, fatigue is reduced with those using it being less tired after a session of airway clearance with NIV as compared without NIV. Maximal inspiratory mouth pressures, as an indicator of respiratory muscle strength, and oxygen saturations are maintained, and respiratory rate is lower during treatment with NIV. ${ }^{29}$ NIV has been shown to improve oxygenation during physiotherapy for airway clearance ${ }^{29,30}$ but has not demonstrated an increased sputum clearance despite patients reporting easier sputum clearance. ${ }^{29,30}$ The evidence for the routine use of NIV to aid airway clearance is insufficient with no large-scale randomized controlled trial (RCTs), ${ }^{28}$ however, it may be useful for certain individuals.

Intermittent positive pressure breathing (IPPB) provides intermittent pressure ventilation to augment lung expansion, to deliver aerosol medication, or to assist ventilation and is a form of NIV. IPPB is used in a similar way to that described above for NIV and has widely been replaced by the use of 
NIV. NIV has proven to be a more adaptable technique, which is used for overnight, acute, and chronic ventilation, as well as for airway clearance. IPPB does not have this adaptability but is still considered for use with atelectasis, impaired secretion clearance, or to deliver aerosol medications where there is respiratory muscle weakness or severe hyperinflation. ${ }^{31}$ There is little evidence for the specific use of IPPB in those with $\mathrm{CF}^{5}$

The devices required to deliver NIV or IPPB are larger and more expensive as compared with PEP or oscillating PEP. There is a reported patient preference for the use of $\mathrm{NIV}^{29}$ but a long-term study, where the participant uses the technique at home, has not been conducted. The practicalities of using a less portable device in the long-term home situation rather than in hospital may alter patient preference. NIV and IPPB tend to remain techniques that are used acutely for those who are struggling with airway clearance due to fatigue, in those with significant atelectasis, and in those who also use NIV for reasons of respiratory failure or nocturnal hypoventilation.

The use of NIV for airway clearance has been a relatively recent development in the use of this equipment. NIV has been described for use in those with CF since the 1990s with the publication of the article "nasal intermittent positive pressure ventilation, a potential bridge to heart-lung transplant". ${ }^{32}$ This "bridge to transplant" use of NIV continues although there are many indications for considering instigation of this treatment in $\mathrm{CF}$ including acute or chronic respiratory failure, nocturnal hypoventilation, during pregnancy, during or postsurgical procedure, and as an adjunct to physiotherapy.

NIV is used for the above indications in many CF units, but the evidence for its use is still not solid. In 2002, published British Thoracic Society guidance stated that, "there are no RCTs of NIV versus conventional treatment in these patient groups (CF/bronchiectasis)". ${ }^{28}$ The guidance also stated that, "NIV can be used as an adjunct to physiotherapy, but evidence for its effectiveness in clearing secretions is lacking." The guidelines summarize that, "there is insufficient evidence to recommend its routine use in these patients." However, these guidelines do not rule out the use of NIV in this patient group despite this lack of evidence by recommending that, "a trial of NIV may be undertaken in patients with a respiratory acidosis $(\mathrm{pH}<7.35)$ secondary to an acute exacerbation of bronchiectasis but excessive secretions are likely to limit it's effectiveness and it should not be used routinely." The American Thoracic Society guidelines ${ }^{33}$ do not discuss NIV in relation to CF specifically but do indicate that most patients in acute respiratory failure should be given the opportunity of a trial of NIV. They also refer to the use of NIV as a ceiling of treatment in patients who are not suitable to be intubated where there is a suggestion that NIV can reduce dyspnea and preserve patient autonomy, given careful and selective application. Both the British and American guidelines suggest that NIV may be used during exercise with the rationale of decreasing dyspnea, improving oxygenation and thereby improving exercise tolerance. There is no current objective evidence at present to support this. Since the publication of these guidelines a RCT has been carried out. ${ }^{34}$ This trial of six weeks of nocturnal NIV in eight adult patients with stable CF with awake hypercapnia demonstrated improvements in chest symptoms, dyspnea, nocturnal hypoventilation, and exercise capacity following the intervention period with NIV.

NIV can be a difficult treatment for some people with CF to accept. It involves more equipment at home, may initially be uncomfortable, and may interfere with the person's lifestyle particularly where it is needed for overnight use. It is vital that the use and setup of NIV are tailored to the individual with thought about the timing of introduction, the timing of use, and the type of ventilator and interface. These issues can greatly affect acceptance and success of NIV. Ongoing assessment is needed to ensure that the use of NIV is successful and that the person using it is able to balance use with the demands of other treatments such as overnight feeds.

\section{Exercise}

Exercise, or physical training, is the participation in a program of regular vigorous physical activity designed to improve physical function, cardiovascular performance, or muscle strength. ${ }^{2}$ Exercise programs may consist of cardiovascular exercise, strengthening, flexibility, posture, speed, and skill work.

Short-term studies suggest that exercise alone is inferior to conventional physiotherapy in terms of airway clearance; ${ }^{6}$ however, the addition of exercise to conventional physiotherapy gives enhanced clearance as compared with conventional physiotherapy alone, ${ }^{35-38}$ and was preferred by patients. ${ }^{36}$

Exercise can be a popular choice among people with $\mathrm{CF}$ as an airway clearance technique. It is considered a "normal" activity by many and participation can be as part of a group activity with friends unlike other physiotherapy interventions. Exercise can be a low-cost intervention and is relatively easy to adapt to clinical status.

Aside from its use as an airway clearance intervention, exercise to increase cardiovascular fitness may alleviate dyspnea and depression and may improve exercise tolerance, management of diabetes, body image, pulmonary function, and delay the onset of osteoporosis. ${ }^{2}$ Positive effects of aerobic and anaerobic training programs may increase exercise 
capacity, strength, and lung function. Physical training may also aid management of CF-related diabetes, delay onset of osteoporosis, and lead to an improved body image and decreased anxiety. Past studies are however short-term and are not consistent in their findings. Therefore it remains unclear as to whether aerobic, anaerobic, or a combination of both is optimal, and there is no evidence to guide prescription of training programs in those patients with CF complications. ${ }^{2}$ Research assessing the potential benefits of exercise should be a priority as it is associated with health management in the general population rather than associated with the condition of $\mathrm{CF}$. Many people with CF who wish to lead a life that fits in with those of their peers therefore identify with this technique.

\section{High-frequency chest wall oscillation}

HFCWO is known by a number of other terms including high-frequency chest wall compression (HFCWC) and the vest. HFCWO is a technique using a pneumatic vest that fits over the thorax and that inflates to a positive pressure with superimposed air pressure oscillations, which induce rapid movement of air in and out of the lungs. ${ }^{39}$

Past research assessing the effectiveness of HFCWO has demonstrated conflicting findings. A number of studies have found the effectiveness of HFCWC to be equal to that of $\mathrm{CCPT}^{7}$ whereas some studies have favored HFCWO over conventional physiotherapy. ${ }^{40-42}$ A more recent UK study of the use of HFCWO during an exacerbation found its efficacy to be less than that of the persons' usual technique in terms of sputum clearance. ${ }^{43}$ A preference for this technique over CCPT has been reported $;{ }^{7}$ however in one study, the participants' perception was that their usual airway clearance technique was more effective. ${ }^{43}$ A long-term trial is currently underway in Canada, and this may give further information about the efficacy of HFCWO. ${ }^{44}$

The costs of HFCWO are substantially greater than the that of other techniques such as ACBT, AD, PEP and oscillating PEP. It may be difficult to justify this higher cost as the technique has not been consistently proven to be superior. It is also a larger device that may be noisier and less portable than the alternatives. As with the other airway clearance techniques, there is a need to individually assess whether HFCWO may be a useful technique.

\section{Other less commonly used techniques}

Mechanical inexsufflation, also known as cough assist, delivers positive pressure followed by negative pressure via a mask, mouthpiece, etc to the airways. ${ }^{45}$ A single small-scale observational study assessing the use of cough assist found no benefit to the use of cough assist in adults with $\mathrm{CF}^{46}$ This may be a technique to consider where there are difficulties gaining optimal airway clearance with the more commonly used techniques. Cough assist is a relatively expensive and less portable device and may therefore be difficult for people with CF to use as a long-term airway clearance technique.

IPV provides a constant mean airway pressure maintaining partial inspiration whilst internally percussing the airways and combining this effect with aerosol inhalation. This is achieved by delivering high-flow jets of gas by pneumatic flow interrupter combined with a sidestream of room air and nebulized medication via a jet venturi. ${ }^{47}$

Small-scale short-term studies comparing IPV with conventional physiotherapy, ${ }^{47-51}$ flutter, ${ }^{48}$ and $\mathrm{HFCWC}^{49}$ agree that IPV is as effective as the alternative techniques. Over a 6-month period, IPV has been shown to be as effective as conventional physiotherapy. ${ }^{47}$ IPV is a technique using a device that is larger, noisier, and more expensive than alternative techniques. There is a suggestion that there may be a preference toward IPV over conventional physiotherapy, ${ }^{50}$ but this preference may be different if assessed in longer term studies conducted in the home situation.

Respiratory muscle training has been developed as an airway clearance technique following studies assessing the use of a fixed-load method to assess inspiratory muscle function and as its use for inspiratory muscle training. During these studies, participants reported increased sputum expectoration using repeated inspiratory maneuvers. It has been hypothesized that this effect may be similar to that seen with exercise. ${ }^{52}$ Studies looking at the effects of inspiratory muscle training show positive effects on sputum expectoration, lung function, exercise capacity, inspiratory muscle strength, and endurance and anxiety or depression scores. ${ }^{52-54}$ The clinical relevance of improved inspiratory muscle strength or endurance has not been demonstrated, and this technique is not used routinely. The equipment involved ranges from relatively inexpensive and portable to more expensive devices that are less portable.

The use of the three techniques identified would need to be individually assessed and monitored very carefully due to the lack of data for their use in those with CF. However as the presentation of CF can vary dramatically, these less commonly used devices and other newly developed techniques should be considered if more standard techniques fail.

\section{Choosing an airway clearance technique}

The wide range of techniques available assists the physiotherapist and person with CF to tailor the airway clearance 
regimen to the person and his/her lifestyle, as well as clinical status, but so much choice can also lead to a confusion as to which technique to use and why. Recent guidance recommends that self-administered techniques should be the first-line airway clearance techniques offered to improve the adherence to treatment and that patient preference for techniques should be considered to improve the adherence to treatment. Current evidence demonstrates little difference in effectiveness between many contemporary airway clearance techniques $^{5,6,21}$ and so factors other than effectiveness will affect the choice of techniques.

\section{Is the technique suitable for the person's clinical status and for their environment?}

Some techniques lend themselves well to particular stages of the condition spectrum of CF. There is little evidence for which stage each technique may be most appropriate, but there are common practices and some practicalities that can guide choice of techniques according to clinical status. At the mild end of the disease spectrum, issues such as adherence and having a lifestyle similar to peers tend to be important. Techniques such as exercise, ACBT, AD, and PEP that minimize treatment burden are relatively simple and do not involve bulky or noisy equipment and are therefore favored. For those with more advanced disease, symptoms may become more of an issue and, therefore, other techniques, for example, the use of NIV to minimize breathlessness, may be introduced. Some techniques may be challenging to use outside of the hospital environment because of the requirement of equipment. For example, IPPB requires oxygen cylinders and adapters to be used at home; therefore, NIV may be favored.

\section{Does the technique fit in with the person's lifestyle?}

Different techniques have characteristics that may fit in with specific lifestyles. Some devices, for example, PEP or oscillating PEP, are small allowing portability for those who may move between houses, for example, when splitting time between parent's and partner's house, whereas other devices such as HFCWO and IPV devices are less portable. Some techniques such as ACBT, AD, PEP, oscillating PEP, HFCWO, NIV, and IPV allow more independence, although some patients like the contact and time with others that assisted techniques such as conventional physiotherapy give. When living in halls at university or a flat, many patients will consider the noise level of the technique a priority. Some techniques such as conventional physiotherapy, HFCWO,
NIV, IPV, and some oscillating PEP devices may be noisier than the acceptable level by patients; therefore quieter techniques or devices such as AD, ACBT, or PEP may be more suitable. Open discussion about the person's lifestyle and encouraging them to discuss ongoing lifestyle changes is vital to help them to choose an appropriate technique for different periods of their life.

\section{Does the person like the technique?}

Consistent adherence to a technique is essential for it to be effective. There have been repeated suggestions that personal preference for a technique may be of paramount importance. ${ }^{7}$ Preference for specific techniques has been suggested in the literature; however individuals will respond differently to each technique. Preference may be associated with issues raised about matching technique to lifestyle but may also be about less identifiable issues, such as patient beliefs about the technique, other patients' experiences and appearance of the device.

\section{Does the person think that the technique works?}

A technique may fit in with the person's lifestyle, he/she may like the technique, and clinically it may have an effect, yet despite this, the person using the technique may believe that it is not working. This tends to affect adherence but does not always require a technique change. This situation may occur where the technique has recently been changed, for example from conventional physiotherapy to a PEP device, as the way the technique feels to the person is different even if it is as effective. It is important that there is education about the new technique and agreed outcome measures to monitor effectiveness to try to resolve this situation. If the person still feels that the technique is not working then a change of technique would be needed.

\section{Is the technique affordable?}

In the UK, airway clearance devices are generally provided free of charge as part of the specialist care provision within National Health Service (NHS) hospitals. However, there is a cost to the NHS that needs to be considered and justified. In countries where a health care service associated with an insurance scheme or where airway clearance devices must be bought privately, costs will need to be considered so that people with $\mathrm{CF}$ can access the recommended device. Some techniques such as conventional physiotherapy, ACBT, and AD cost only the time taken by the physiotherapist to teach and review the technique. Other techniques utilize relatively low cost devices, for example, PEP and oscillating PEP. Lastly, there are techniques that 
are more costly and may also involve the ongoing purchase of consumables, for example, HFCWO, IPV, and NIV. Cost will not be the primary reason for choice of techniques; however it is difficult to justify the use of more expensive techniques unless additional benefit, efficacy and preference are shown over the simpler and less costly techniques.

\section{Posture}

Postural disorders in CF are secondary to pulmonary disease and the complex relationship between posture and respiration. ${ }^{55-57}$ Thoracic kyphosis, vertebral wedging, decreased thoracic mobility, and muscle weakness are more common in those with CF and are related to worsening lung function and clinical symptoms. ${ }^{55,57}$ These changes are likely to be due to an increased work of breathing and the flexed posture assumed during excessive coughing. ${ }^{57}$

The major consequence of postural disorders is back pain, and the severity of this pain is associated with pulmonary deterioration, sputum production, and breathlessness. Postural disorders may be responsive to therapy and therefore be reversible. ${ }^{55}$ Assessment and an appropriate program of chest mobility and strengthening exercises to improve posture and coordination significantly improve the posture, chest wall mobility and body strength, reduce the need for intravenous antibiotics and slow the reduction of forced expiratory volume in one second. ${ }^{58}$

Despite these benefits, postural assessment and treatment are often neglected by people with $\mathrm{CF}$ and their clinicians. This may be due to the evidence for its benefit being relatively recent and so it has not yet become an integrated aspect of management within a regimen, which is high burden even without the addition of postural treatment.

\section{Continence}

The prevalence of urinary incontinence (UI) in women with $\mathrm{CF}$ is higher than the normal population ${ }^{59-62}$ and higher than in other respiratory patient groups. ${ }^{63}$ The major cause of UI is coughing and symptoms impact mainly on the ability to perform airway clearance and lung function testing. Symptoms are under reported and subjects are unlikely to seek help with the problem. There appears to be no problem with the timing of pelvic floor muscle activity or maximum muscle activity during huffing and coughing. However, muscle endurance is reduced during prolonged coughing, which may be the cause of the increased prevalence in those with $\mathrm{CF}^{64}$

Despite the strong evidence for a high prevalence of UI in those with CF, there are few reports of the assessment and treatment of the problem. However there is evidence that suggests that the problem is reversible with treatment. One study examined the effect of a three-month individualized pelvic floor muscle exercise program on the strength and endurance of the pelvic muscles ${ }^{65}$ and found that this program reduced symptoms and improved muscle endurance. Another study reported improved electromyography activity over one and twenty seconds and a decrease in symptoms maintained over three months after intervention, following a comprehensive program of pelvic floor muscle exercises and electrical stimulation. ${ }^{64}$

\section{Inhalation therapy}

Inhalation therapy offers two major advantages: direct transmission of the drug to the target area and the potential to reduce the dose of the drug so minimizing any undesirable side effects. ${ }^{66}$ The advantages of delivering medication in this way have led to a rapid expansion in the number of medications delivered by inhalation so increasing the importance of ensuring that delivery is optimized. Optimizing inhalation therapy encompasses a variety of factors such as type of medication and it's effects on the airways, mucociliary clearance, exercise tolerance, and dyspnea, device characteristics, timing of delivery, technique during delivery, burden of treatment and adherence.

Medications prescribed by this route include antibiotics, mucolytics, bronchodilators, steroids, and antifungals, as well as treatments in development such as gene therapy which also use the inhaled route. Deposition is an important factor in the effectiveness of each of these medications when delivered by inhalation. Particle sizes of two-six microns are required to target the upper and central airways that give best clinical effect. Particles greater than six microns tend to be deposited in the mouth and esophageal region with no clinical effect, and particle sizes less than two microns show deposition in the peripheral airways and alveoli with only some local clinical effect but high systemic absorption. ${ }^{67}$ Therefore, it is vital to consider the ability of a device to deliver a high proportion of optimally sized particles.

\section{Inhalers}

Some inhaler devices are more acceptable than others to patients. This needs to be balanced against clinical efficacy and the availability of medications through particular devices. Drug deposition and delivery are directly influenced by inspiratory flow rate. Patients who cannot achieve the recommended inspiratory flow for their inhaler may not gain maximum benefit from the prescribed drug. Metereddose aerosol inhalers (MDIs) are least prone to this effect especially when coupled with a spacer device. However this bulky combination may be less acceptable to people with $\mathrm{CF}$. 
Breath-actuated MDIs release the dose of medication above the specific flow rate; below this the person will not receive the medication. However, this type of device decreases issues with technique specifically around coordination between inspiration and actuation of the device. Dry-powder inhalers are also dependent on sufficient inspiratory flow to remove medication from the device; deposition greatly reduces with a decreased peak inhalation rate..$^{68,69}$

\section{Nebulizers}

Nebulizers deliver greater doses of medication than inhalers and some medications are, at present, only available for delivery by nebulization. There are a number of types of nebulizer system, the most simple of which is a compressor and nebulizer chamber system considered to be a conventional system. The compressor entrains room air, compresses it to a higher pressure and emits the air at a given flow rate. Air enters the nebulizer chamber and passes through a small hole, a venturi, beyond which the air expands rapidly creating a negative pressure that sucks the medication up a feeding tube where it is atomized into particles. The particle sizes are variable, larger particles impacting on the baffle within the nebulizer chamber and the walls of the chamber and returned back to the well of the chamber. The smaller particles are continuously released from the nebulizer chamber during both inspiration and expiration by the person using the nebulizer system. These systems are relatively cheap but tend to be noisy, bulky, require a power source and the particle size produced is variable. Because they deliver continuously, there is significant wastage of medication and treatment times may be prolonged.

Ultrasonic nebulizers use a piezoelectric crystal that vibrates creating standing waves within the surface of the medication and droplets move away from the crests of these waves becoming an aerosol. Large particles impact on a baffle to be renebulized in the same way as a conventional nebulizer. Ultrasonic nebulizers may be smaller and are quieter and quicker than conventional systems. However, there is controversy as to whether they are suitable to nebulize certain medications.

Newer technologies have been developed to produce homogenous particle sizes and to increase speed of nebulization. Vibrating mesh technologies aerosolize medication using a vibrating, perforated mesh to generate particles. Vibrating mesh systems are silent, portable being small, battery powered and fast and produce more homogenously sized particles as compared with conventional systems. Adaptive aerosol delivery devices analyze pressure changes relating to airflow and deliver timed pulses of aerosol during the first $50 \%-80 \%$ of inspiration until the preset dose is delivered. This eliminates wastage of medication during exhalation, which occurs with continuously delivering nebulizers and optimizes deposition. These devices are smaller, quieter, and quicker than conventional systems. They also allow download of adherence data including date, time, and duration of each nebulization dose taken, as well as whether the dose was complete. This can allow a clear picture of how people engage with treatment and can assist tailoring of treatment regimens.

\section{Timing of medication}

There are few hard and fast rules in the timing and order of inhaled medications. Often the effects of the drug and time to peak action vary from person to person; therefore advice regarding timing is individualized to each person following a period of assessment. Possibly the most important point regarding inhaled medication is adherence. Therefore, timing medications with consideration for a balance between clinical effectiveness with the patient's lifestyle, commitments and priorities is the ideal.

There are however some recognized practices with regards to timing of inhaled medications. Firstly, dornase alpha is a protein and may be denatured where it comes in contact with nebulized antibiotics. Therefore, it is advised that a break of at least an hour is observed between these two nebulized medications. There is some published work looking at timing of dornase alpha around airway clearance; one study suggests that it is equally effective whether inhaled thirty minutes before or after airway clearance, ${ }^{70}$ whereas another study suggests that inhalation thirty minutes before airway clearance improves small airway function to a greater extent than inhalation thirty minutes after airway clearance. ${ }^{71}$ It has also been demonstrated that longer time periods of over six hours between administration of dornase alpha and airway clearance may be more effective than less than six hours. ${ }^{72}$ However, there is agreement between these papers that those using dornase alpha should take it regularly and at a time convenient to their lifestyle but at least thirty minutes before airway clearance. A protocol has been published for a systematic review of the evidence regarding timing of dornase alpha, and publication of this review may further guide practice. ${ }^{73}$

It is recognized, but not proven, that nebulized antibiotics are best taken after airway clearance to ensure that they are not prematurely cleared from the airways. Bronchodilators may increase the ease of chest clearance and exercise by improving airway patency and, if prescribed, may be useful to take before these activities. 


\section{Oxygen}

Progressive lung damage seen in those with CF ultimately leads to chronic hypoxemia. This is defined as a partial pressure of oxygen in the blood of less than $8 \mathrm{kPa}$ or $60 \mathrm{~mm}$ of mercury or where the oxygen saturation of arterial hemoglobin is less than $90 \% .{ }^{74}$ Chronic hypoxemia can lead to pulmonary hypertension and cor pulmonale. Nocturnal hypoxemia, which is demonstrated in $\mathrm{CF}^{75-78}$ may be associated with decreased daytime function in patients with $\mathrm{CF}^{79,80}$

Hypoxemia can be eliminated with supplemental oxygen, but the benefits of this have not yet been demonstrated. ${ }^{74}$ It has been shown that oxygen therapy increases function as measured by days at work or school, ${ }^{81}$ but effects have not been seen in survival or lung or cardiac function. ${ }^{74}$ The addition of supplemental oxygen therapy during exercise improves oxygenation and increases exercise tolerance and aerobic capacity. ${ }^{74,82}$ There remains uncertainty about when to instigate oxygen therapy and what the long-term effects are. Where it is prescribed, the practical application of oxygen therapy can be complex. ${ }^{83,84}$ People with $\mathrm{CF}$ therefore require meticulous evaluation and detailed specific prescriptions, with relevant assessment for ambulatory oxygen ${ }^{83}$ ensuring access to oxygen devices that will allow a complete lifestyle.

\section{Physiotherapy: the future}

Numerous physiotherapy techniques have been developed and there is a realization that one of the greatest challenges is for people with $\mathrm{CF}$ to be able to adhere to treatment regimens that may be complicated and/or time-consuming. ${ }^{86} \mathrm{It}$ is likely therefore that future developments and research of physiotherapy techniques will focus on patient satisfaction, quality of life, and adherence. This may involve developing the techniques available to make any devices involved smaller, quieter, easier to use and generally more acceptable to people with $\mathrm{CF}$.

\section{Conclusion}

As life expectancy for those with CF increases, so additional complications are seen which require additional management strategies, which in turn increase the burden of treatment. The pressures of treatment increasingly come into competition with the time and effort required to participate in a complete lifestyle and physiotherapy balances precariously between these competing pressures. The techniques including airway clearance, exercise, inhalation therapy, oxygen therapy, and NIV used by physiotherapists are often some of the most time-consuming, visual to others and poorly adhered to aspects of the management of CF. Yet, these elements of management also help to achieve the clinical status required for people with CF to lead a complete lifestyle.

Physiotherapists in clinical practice are aware of the importance of tailoring management strategies to the individual. It should also be accepted that this individual tailoring of a physiotherapy routine should be an ongoing process as the needs of the person with CF change over time. Research into physiotherapy techniques to date has tended to assess efficacy of one technique over another with little attention to patientreported outcomes. These studies have not demonstrated a clear "gold standard" technique to use instead they have suggested a similar efficacy between most of the commonly used techniques. There are suggestions both from past studies and in clinical practice that patient preference, lifestyle, and adherence are important in the success of a technique and future research should focus on these outcomes. This may further assist clinical teams, including physiotherapists and people with $\mathrm{CF}$, to tailor treatment plans to the individual.

\section{Disclosure}

Tracey Daniels provides advice as a consultant to Philips on nebulizer and associated technology development, to Novartis and Pharmaxis on inhaled therapies, and to Air Products on home oxygen provision.

\section{References}

1. Dodge JA, Lewis PA, Stanton M, et al. Cystic fibrosis mortality and survival in the UK: 1947-2003. Eur Respir J. 2007;29:522-526.

2. Bradley J, Moran F. Physical training for cystic fibrosis. Cochrane Database Syst Rev. 2002;(1):CD002768. doi:10.1002/14651858. CD002768.pub2.

3. Thomas J, Cook DJ, Brooks D. Chest physical therapy management of patients with cystic fibrosis. A meta-analysis. Am J Respir Crit Care Med. 1995;151(3):846-850.

4. van der Schans CP, Prasad A, Main E. Chest physiotherapy compared to no chest physiotherapy for cystic fibrosis. Cochrane Database Syst Rev. 2000;(2);CD001401. doi:10.1002/14651858.CD001401.

5. Bott J, Blumenthal S, Buxton M, et al. Guidelines for the physiotherapy management of the adult, medical, spontaneously breathing patient, Joint BTS/ACPRC Guideline. Thorax. 2009;64 Supp1:i1-i52.

6. Flume PA, Robinson KA, O'Sullivan BP, et al. Cystic fibrosis pulmonary guidelines: airway clearance therapies. Respir Care. 2009;54:522-537.

7. Main E, Prasad A, van der Schans CP. Conventional chest physiotherapy compared to other airway clearance techniques for cystic fibrosis. Cochrane Database Syst Rev. 2005;(1):CD002011. doi:10.1002/14651858.CD002011.pub2.

8. Webber BA, Pryor JA. Physiotherapy for respiratory and cardiac problems. Edinburgh, New York: Churchill Livingstone; 1993.

9. Pryor JA, Webber BA, Hodson ME, et al. Evaluation of the forced expiration technique as an adjunct to postural drainage in treatment of cystic fibrosis. Br Med J. 1979;2:417-418. 
10. Williams MT, Parsons DW, Frick RA, et al. Acute respiratory infection in patients with cystic fibrosis with mild pulmonary impairment: comparison of two physiotherapy regimens. Aust J Physiother. 2001;47:227-236.

11. Miller S, Hall DO, Clayton CB, et al. Chest physiotherapy in cystic fibrosis: a comparative study of autogenic drainage and the active cycle of breathing techniques with postural drainage. Thorax. 1995;50:165-169.

12. Pryor JA, Webber BA, Hodson ME, Warner JO. The Flutter VRP1 as an adjunct to chest physiotherapy in cystic fibrosis. Respir Med. 1994;88:677-681.

13. Pryor JA, Webber BA. Physiotherapy and paramedical issues. In: Hodson ME, Geddes D, editors. Cystic Fibrosis. 2nd ed; 2000.

14. Davidson AG, Wong LT, Pirie GE, et al. Long-term comparative trial of conventional percussion and drainage physiotherapy versus autogenic drainage in CF. Pediatr Pulmonol. 1992;14:298.

15. McIlwaine PM, Davidson AG, Wong LT, et al. The effect of chest physiotherapy by postural drainage and autogenic drainage on oxygen saturation in cystic fibrosis. Pediatr Pulmonol. 1991;11:291.

16. Elkins MR, Jones A, van der Schans CP. Positive expiratory pressure physiotherapy for airway clearance in people with cystic fibrosis. Cochrane Database Syst Rev. 2006;(2):CD003147. doi:10.1002/14651858.CD003147.pub3.

17. Andersen JB, Qvist H, Kann T. Recruiting collapsed lung through collateral channels with positive end-expiratory pressure. Scan J Respir Dis. 1979;60:260-266.

18. Groth S, Stafanger G, Dirksen H, Andersen JB, Falk M, Kelstrup M. Positive expiratory pressure (PEP-mask) physiotherapy improves ventilation and reduces volume of trapped gas in cystic fibrosis. Bull Eur Physiopathol Respir. 1985;21(4):339-343.

19. Oberwaldner B, Evans JC, Zach MS. Forced expirations against a variable resistance: a new chest physiotherapy method in cystic fibrosis. Pediatr Pulmonol. 1986;2:358-367.

20. Falk M, Kelstrup M, Andersen JB, et al. "Improving the ketchup bottle method with positive expiratory pressure, PEP, in cystic fibrosis". Eur J Respir Dis. 1984;65(6):423-432.

21. Pryor JA, Tannenbaum E, Cramer D, et al. A comparison of five airway clearance techniques in the treatment of people with cystic fibrosis J Cyst Fibrosis. 2006;5:S76.

22. Costantini D, Brivio A, Brusa D, Delfino R, Fredella C, Russo M. PEP-mask versus postural drainage in CF infants a long-term comparative trial. Pediatr Pulmonol. 2001;Suppl 22:308.

23. McIlwaine PM, Wong LT, Peacock D, Davidson AGF. Long-term comparative trial of positive expiratory pressure versus oscillating positive expiratory pressure (flutter) physiotherapy in the treatment of cystic fibrosis. J Pediatr. 2001;138(6):845-850.

24. Hofmeyr JL, Webber BA, Hodson ME. Evaluation of positive expiratory pressure as an adjunct to chest physiotherapy in the treatment of cystic fibrosis. Thorax. 1986;41:951-954.

25. Pfleger A, Theissl B, Oberwaldner B, et al. Self-administered chest physiotherapy in cystic fibrosis: a comparative study of high-pressure PEP and autogenic drainage. Lung. 1992;170:323-330.

26. Konstan MW, Stern RC, Doershuk CF. Efficacy of the flutter device for airway mucus clearance in patients with cystic fibrosis. J Pediatr. 1994;124(5 Pt 1):689-693.

27. Volsko TA, DiFiore J, Chatburn RL. Performance comparison of two oscillating positive expiratory pressure devices: acapella versus flutter. Respir Care. 2003;48(2):124-130.

28. British Thoracic Society Standards of Care Committee. Non-invasive ventilation in acute respiratory failure. Thorax. 2002;57:192-211.

29. Holland AE, Denehy L, Ntoumenopoulos G, et al. Non-invasive ventilation assists chest physiotherapy in adults with acute exacerbations of cystic fibrosis. Thorax. 2003;58:880-884.

30. Moran F, Bradley J, Piper AJ, et al. Non-invasive ventilation for cystic fibrosis. Cochrane Database Syst Rev. 2003;(2):CD002769. doi:10.1002/14651858.CD002769.pub2.
31. Sorenson HM, Shelledy DC. AARC Clinical practice guideline. Intermittent positive pressure breathing. 2003 revision. Respir Care. 2003;48(5):540-546.

32. Hodson ME, Madden BP, Steven MH, Tsang VT, Yacoub MH. Noninvasive mechanical ventilation for cystic fibrosis patients - a potential bridge to transplantation. Eur Respir J. 1991;4(5):524-527.

33. American Thoracic Society. International consensus conferences in intensive care medicine: Non-invasive positive pressure ventilation in acute respiratory failure. Am J Respir Crit Care Med. 2000;163:283-291.

34. Young AC, Wilson JW, Kotsimbos TC, Naughton MT. Randomised placebo controlled trial of non-invasive ventilation for hypercapnia in cystic fibrosis. Thorax. 2008;63(1):72-77. Epub 2007 Aug 3.

35. Salh W, Bilton D, Dodd M, et al. Effect of exercise and physiotherapy in aiding sputum expectoration in adults with cystic fibrosis. Thorax. 1989;44:1006-1008.

36. Bilton D, Dodd ME, Abbot JV, et al. The benefits of exercise combined with physiotherapy in the treatment of adults with cystic fibrosis. Respir Med. 1992;86:507-511.

37. Baldwin DR, Hill AL, Peckham DG, et al. Effect of addition of exercise to chest physiotherapy on sputum expectoration and lung function in adults with cystic fibrosis. Respir Med. 1994;88:49-53.

38. Lannefors L, Wollmer P. Mucus clearance with three chest physiotherapy regimes in cystic fibrosis: a comparison between postural drainage, PEP and physical exercise. Eur Respir J. 1992;5:748-753.

39. Dosman CF. High-frequency chest compression: a summary of the literature. Can Respir J. 2005;12(1):37-41.

40. Kraig R, Kirkpatrick KR, Howard D, et al. A direct comparison of manual chest percussion with acoustic percussion, an experimental treatment for cystic fibrosis. Am J Respir Crit Care Med. 1995;151:P738.

41. Kluft J, Beker L, Castagnino M, Gaiser J, Chaney H, Fink RJ. A comparison of bronchial drainage treatments in CF. Pediatr Pulmonol. 1995;22:271-274.

42. Warwick WJ, Weilinski CL, Hansen LG. Comparison of expectorated sputum after manual chest physical therapy and high frequency chest compression. Biomed Instrum Technol. 2004;38(6):470-475.

43. Osman LP, Roughton M, Hodson ME, et al. High frequency chest wall oscillation in cystic fibrosis. J Cyst Fibros. 2008;7:S73.

44. Bradley J. High frequency chest wall oscillation in Cystic Fibrosis. Thorax. 2010;65:189-190.

45. Lapin CD. Assisted cough devices. Pediatr Pulmonol Suppl. 2004;26:149-151

46. Agent P, Ross E, Chatwin M. The use of mechanical insufflationexsufflation on peak cough flow in adults with cystic fibrosis. $J$ Cyst Fibros. 2003.

47. Homnick DN, White F, de CC. Comparison of effects of an intrapulmonary percussive ventilator to standard aerosol and chest physiotherapy in treatment of cystic fibrosis. Pediatr Pulmonol. 1995;20:50-55.

48. Newhouse PA, White F, Marks JH, Homnick DN. The intrapulmonary percussive ventilator and flutter device compared to standard chest physiotherapy in patients with cystic fibrosis. Clin Pediatr. 1998;37(7):427-432.

49. Varekojis SM, Douce FH, Flucke RL, et al. A comparison of the therapeutic effectiveness of and preference for postural drainage and percussion, IPV and HFCWC in hospitalised CF patients. Respir Care. $2003 ; 48(1): 24-28$

50. Marks JH, Hare KL, Saunders RA, et al. Pulmonary function and sputum production in patients with cystic fibrosis: a pilot study comparing the PercussiveTech HF device and standard chest physiotherapy. Chest. 2004;125:1507-1511.

51. Natale JE, Pfeifle J, Homnick DN. Comparison of intrapulmonary percussive ventilation and chest physiotherapy. A pilot study in patients with cystic fibrosis. Chest. 1994;105:1789-1793.

52. Chatham K, Ionescu AA, Nixon LS, et al. A short-term comparison of two methods of sputum expectoration in cystic fibrosis. Eur Respir J. 2004;23:435-439. 
53. Enright $\mathrm{S}$, Chatham $\mathrm{K}$, Ionescu AA, et al. Inspiratory muscle training improves lung function and exercise capacity in adults with cystic fibrosis. Chest. 2004;126:405-411.

54. Innes-Asher M, Pardy RL, Coates AL, et al. The effects of inspiratory muscle training in patients with cystic fibrosis. Am Rev Respir Dis. 1982;126:855-859.

55. Tattersall R, Walshaw MJ. Posture and cystic fibrosis. J R Soc Med. 2003;96 Suppl 43:18-22.

56. Massery M. Musculoskeletal and neuromuscular interventions: a physical approach to cystic fibrosis. J R Soc Med. 2005;98 Suppl 45: 55-66.

57. Rose J, Gamble J, Schultz A, et al. Back pain and spinal deformity in cystic fibrosis. Am J Dis Child. 1987;141:1313-1316.

58. Demryl A, Ami S, Levi M, et al. Chest strength and mobility training: a new approach to airways clearance. J Cyst Fibros. 2006;5:S82.

59. White D, Stiller K, Roney F. The prevalence and severity of symptoms of incontinence in adult cystic fibrosis patients. Physiother Theory Pract. 2000; $16: 35-42$.

60. Cornacchia 2001 Cornaccia M, Zenorini A, Braagion C, et al. Prevalence of urinary incontinence in women with cystic fibrosis. BJU Int. 2001;88:44-48.

61. Orr A, McVean R, Webb AK. A questionnaire survey of the prevalence of urinary incontinence in females with cystic fibrosis: a marginalised and undertreated problem. Br Med J. 2001;322:1521.

62. Moran F, Bradley JM, Boyle L, Elborn JS. Incontinence in adult females with cystic fibrosis: a Northern Ireland survey. Int J Clin Pract. 2003;57:182-183.

63. Button BM, Sherburn M, Chase J, McLachan Z, Wilson J. Incontinence (urinary and bowel) in women with cystic fibrosis compared to chronic obstructive pulmonary disease (COPD) and controls: prevalence, severity and bother. Pediatr Pulmonol. 2004;Suppl 27:a359.

64. Button BM, Sherburn M, Chase J, Stillman B, Wilson J. Effect of a three months physiotherapeutic intervention on incontinence in women with chronic cough related to cystic fibrosis and COPD. Pediatr Pulmonol. 2005;113 Suppl 28:a369.

65. McVean RJ, Orr A, Webb AK, et al. Treatment of urinary incontinence in cystic fibrosis. J Cyst Fibros. 2003;2:171-176.

66. Association of Physiotherapists Working with Cystic Fibrosis and the CF Nurses Group Working Party. Practical Guidelines for the Use of Nebulisers in Cystic Fibrosis. Bexley, Kent: Pharmax Ltd; 1996.

67. Chrystyn H. Is inhalation rate important for dry powder inhalers? Using the in-check dial to identify these rates. Respir Med. 2003;97:181-187.

68. Palander A, Mattila T, Karhu M, Muttonen E. 2000, In vitro comparison of three salbutamol-containing multidose dry powder inhalers: Buventol Easyhaler, Inspiryl Turbuhaler ${ }^{\mathbb{1}}$ and Ventoline Diskus. Clin Drug Inv. 20001;20:25-33.

69. Borgstrom L, Bondesson E, Moren F, Trofast E, Newman SP. Lung deposition of budesonide inhaled via Turbuhaler ${ }^{\mathbb{R}}$ : a comparison with terbutaline sulphate in normal volunteers. Eur Respir J. 1994;7:68-73.
70. Fitzgerald D, Hilton J, Jepson B, Smith L. A crossover, randomised, controlled trial of dornase alfa before versus after physiotherapy in cystic fibrosis. Pediatrics. 2005;116:549-554.

71. van der Giessen LJ, de Jongste JC, Gosselink R, et al. RhDNase before airway clearance therapy improves airway patency in children with $\mathrm{CF}$. Pediatr Pulmonol. 2007;42:624-630.

72. Wilson CJ, Robbins LJ, Murphy JM, Chang AB. Is a longer time interval between recombinant human deoxyribonuclease (dornase alfa) and chest physiotherapy better? A multi-center, randomized crossover trial. Pediatr Pulmonol. 2007;42:1110-1116.

73. Dentice R, Elkins M. Timing of dornase alfa inhalation for cystic fibrosis. Cochrane Database of Syst Rev. 2009;(3):CD007923. doi:10.1002/14651858.CD007923.

74. Elphick HE, Mallory G. Oxygen therapy for cystic fibrosis. Cochrane Database of Syst Rev. 2009;(1):CD003884. doi:10.1002/14651858. CD003884.pub3.

75. Muller NL, Francis PW, Gurwitz D, Levison H, Bryan AC. Mechanisms of hemoglobin desaturation during rapid-eye-movement sleep in normal subjects and in patients with cystic fibrosis. Am Rev Respir Dis. 1980;121(3):463-469.

76. Francis PW, Muller NL, Gurwitz D, Milligan DW, Levison H, Bryan AC. Haemoglobin desaturation: its occurrence during sleep in patients with cystic fibrosis. Am J Dis Child. 1980;134:734-740.

77. Frangolais DD, Wilcox PG. Predictability of oxygen desaturation during sleep in patients with cystic fibrosis. Chest. 2001;119(2):434-441.

78. Milross MA, Piper AJ, Norman M, et al. Predicting sleep-disordered breathing in patients with cystic fibrosis. Chest. 2001;120(4): 1239-1245.

79. Dancey DR, Tullis ED, Heslegrave R, Thornley K, Hanley PJ. Sleep quality and daytime function in adults with cystic fibrosis and severe lung disease. Eur Respir J. 2002;19:504-510.

80. Dobbin CJ, Bartlett D, Melehen K, Grunstein RR, Bye P. The effect of infective exacerbations on sleep and neurobehavioural function in cystic fibrosis. Am J Respir Crit Care Med. 2005;172:99-104.

81. Zinman R, Corey M, Coates AL, et al. Nocturnal home oxygen in the treatment of hypoxemic cystic fibrosis patients. J pediatr. 1989;114(3):368-377.

82. Marcus CL, Bader D, Stabile MW, et al. Supplemental oxygen and exercise performance in patients with cystic fibrosis with severe pulmonary disease. Chest. 1992;101:52-57.

83. British Thoracic Society emergency oxygen guideline group. Guideline for emergency oxygen use in adult patients. Thorax. 2008;63 suppl 6: vi1-vi68.

84. Dodd ME, Haworth CS, Webb AK. "A practical approach to oxygen therapy in cystic fibrosis". J R Soc Med. 1998;91 Suppl 34;30-39.

85. Coates AL. "Oxygen therapy, exercise, and cystic fibrosis". Chest. 1992;101(1):2-4.

86. Quittner AL, Modi AC, Lemanek KL, et al. Evidence-based assessment of adherence to medical treatments in pediatric psychology. $J$ Pediatr Psychol. 2008;33(9):916-936.
Journal of Multidisciplinary Healthcare

\section{Publish your work in this journal}

The Journal of Multidisciplinary Healthcare is an international, peerreviewed open-access journal that aims to represent and publish research in healthcare areas delivered by practitioners of different disciplines. This includes studies and reviews conducted by multidisciplinary teams as well as research which evaluates the results or conduct of such teams or
Dovepress

healthcare processes in general. The journal covers a wide range of areas and welcomes submission from practitioners at all levels, from all over the world. The manuscript management system is completely online and includes a very quick and fair peer-review system. Visit http://www.dovepress.com/testimonials.php to read real quotes from published authors. 